\title{
Prevalence and correlates of depressive symptoms among high school adolescent girls in southern Uganda
}

Proscovia Nabunya* (D), Christopher Damulira, William Byansi, Joelynn Muwanga, Ozge Sensoy Bahar, Flavia Namuwonge, Eloho Ighofose, Rachel Brathwaite, Wilberforce Tumwesige and Fred M. Ssewamala

\begin{abstract}
Background: In sub-Saharan Africa (SSA), adolescent girls and young women are three times more likely than boys to have depressive disorders. Understanding adolescents' unique and common vulnerabilities and protective factors is essential for the development of appropriate interventions and programming focused on child and adolescent mental health. This paper examines the prevalence and predictors of depressive symptoms among high school adolescent girls in southern Uganda.
\end{abstract}

Methods: Baseline data from a longitudinal cluster randomized study involving 1260 adolescent girls (14-17 years), recruited from 47 secondary schools were utilized. Depressive symptoms were estimated using the 21-item Beck's Depression Inventory. Hierarchical linear regression modelling was utilized to estimate key predictors of depressive symptoms among adolescent girls.

Results: Of the total sample, $16.35 \%(n=206)$ reported severe depressive symptoms and almost one in every three adolescent girls interviewed $(29.68 \%, n=374)$ reported moderate symptoms. These symptoms were more prevalent among older adolescents (16 years and above). In addition, family relationships, social support, as well as measures of psychological wellbeing (self-concept and self-esteem) were all associated with lower levels of depressive symptoms. Hopelessness was associated with higher levels of depressive symptoms among adolescent girls.

Conclusion: Findings from this study indicate a high prevalence of depressive symptoms, especially among older adolescent girls. In addition, family support factors and adolescents' psychological wellbeing were associated with low levels of depressive symptoms - pointing to the need to strengthen family functioning and adolescent's psychological wellbeing to mitigate risks. Taken together, findings support increasing calls for early screening and detection of depressive symptoms to facilitate timely referral to care and treatment. Findings may also inform the development and incorporation of gender-specific mental health components in programming targeting adolescent girls, in low-resource communities in SSA.

Trial registration: This trial was prospectively registered with ClinicalTrials.gov (registration number: NCT03307226) on 11 October 2017.

Keywords: Depressive symptoms, Prevalence, Adolescent girls, Uganda, Mental health

\footnotetext{
* Correspondence: nabunyap@wustl.edu

Washington University in St. Louis, Brown School of Social Work, International Center for Child Health and Development (ICHAD), One Brookings Drive, St. Louis, MO 63130, USA
}

C The Author(s). 2020 Open Access This article is licensed under a Creative Commons Attribution 4.0 International License, which permits use, sharing, adaptation, distribution and reproduction in any medium or format, as long as you give appropriate credit to the original author(s) and the source, provide a link to the Creative Commons licence, and indicate if changes were made. The images or other third party material in this article are included in the article's Creative Commons licence, unless indicated otherwise in a credit line to the material. If material is not included in the article's Creative Commons licence and your intended use is not permitted by statutory regulation or exceeds the permitted use, you will need to obtain permission directly from the copyright holder. To view a copy of this licence, visit http://creativecommons.org/licenses/by/4.0/ The Creative Commons Public Domain Dedication waiver (http://creativecommons.org/publicdomain/zero/1.0/) applies to the data made available in this article, unless otherwise stated in a credit line to the data. 


\section{Background}

Mental health disorders account for $16 \%$ of the global burden of disease and injury among children and adolescents between 10 and 19 years of age [1]. Depression is one of the leading causes of illness and disability among adolescents between 10 and 14 years $[1,2]$. In subSaharan Africa (SSA), there is limited epidemiological data on the prevalence of depression in young people [3, 4]. Additionally, there is poor understanding of mental health illness, that disorders such as depression are unrecognized and as such, remain untreated $[5,6]$. On the other hand, studies document considerable levels of other mental health problems among children and adolescents $[7,8]$. It is estimated that 1 in 7 adolescents have significant mental difficulties, with 1 in 10 having a specific psychiatric disorder in SSA [3]. Yet, there are fewer economic and human resources dedicated to the mental health of children and adolescents in the region [9]. Given that most mental health disorders start early in childhood and continue to rise through adolescence [10-13], if unaddressed, these conditions extend to adulthood resulting in poor health outcomes, limiting opportunities for a productive adult life [13, 14].

\section{Risk and protective factors}

Understanding adolescents' unique and common vulnerabilities to depression, as well as protective factors is essential for the development of appropriate interventions and programming focused on child and adolescent mental health. Previous studies have documented the disproportionate prevalence of depression and other mental health disorders among females compared to males [15-19]. Socio-economic factors including poverty, gender-based violence, sexual exploitation, and exclusion from decisionmaking processes increase susceptibility and exposure to mental health risks among adolescent girls and limit their ability to seek, access and use mental health services [2022]. These factors combine with biological, emotional and cognitive processes associated with puberty [23, 24], to further increase the risk of depression among adolescent girls.

In addition, negative thoughts associated with depression influence both individuals' feelings about themselves and their behaviors [25, 26], and can lead to unhealthy decision making [27]. Depressed adolescents are more likely to have low educational attainment, be unemployed and at high risk for death due to suicide $[28,29]$. In addition, adolescents experiencing depression and other mental health issues are more likely to engage in risky behaviors, including unprotected sexual activity, having multiple sexual partners [30-32] and substance abuse [28]. Indeed, depressive symptoms are associated with cumulative HIV incidence among adolescent girls and young women in SSA [33].
A number of individual level and family-level factors have been documented as protective against depressive symptoms. At the individual level, self-esteem has an inverse relationship with depression [34-38], and adolescents with low self- esteem are more likely to be depressed later in life [38-40]. Similar findings have been documented for hopelessness [41, 42]. In addition, the relationship between family and community social capital and mental health outcomes among children and adolescents has been widely documented [43-46]. Social capital in the form of social support, especially from parents/caregivers and family members is consistently associated with adolescent's protection from depression [47-50]. Adolescents reporting high levels of family cohesion, trust and closeness also report better mental health and behavioral outcomes [51-53]. Moreover, parent-child relationships characterized by social support, positive communication, nurturance, parental involvement and low levels of conflict are associated with fewer reported mental health issues among children and adolescents [53-57]. Thus, interventions that target both individual level assets, such as self-esteem and future orientation, as well as family-level resources, including social support to improve the overall mental health functioning of adolescents as they transition into adulthood, are highly critical.

The above studies have mainly been conducted in high income countries. Consistent with other countries in SSA, few studies in Uganda have documented the prevalence of depressive symptoms among young people [58, 59], and among adolescent girls in particular. Available studies have mainly focused on highly vulnerable children and adolescents, such as those orphaned by HIV/ AIDS [60-65], those with chronic conditions [66-70], and traumatized adolescents in war torn and postconflict settings [71, 72]. To our knowledge, only one study has focused on school-going adolescents (14-17 years) in a non-conflict region [73]. Findings from this study indicate prevalence rates of $21 \%$ on the child depression inventory measure, with higher prevalence among adolescent girls compared to boys. This study was however conducted in the central region of Uganda, with a sample of 591 adolescents, within a mix of boarding schools and single sex schools, with slightly different socio-economic status of the students' body, compared to the general student population in Uganda. In addition, this study did not assess social support -which has been documented as an important predictor of mental health wellbeing among individuals, including children and adolescents [43-45, 74].

Thus, this study aims to add to existing limited literature and to address gaps in the prevalence rates and predictors of depressive symptoms among high school adolescent girls in Uganda. More specifically, this study 
aims to address the following research questions: 1) What are the prevalence rates of depressive symptoms among adolescent girls in southern Uganda, a geographical region heavily impacted by HIV/AIDS? 2) Do levels of depressive symptoms vary based on age groups i.e., younger versus older adolescent girls? 3) What are the key individual and family -level predictors of depressive symptoms among adolescent girls? This is an important area of inquiry, as findings may inform the development of and incorporation of gender-specific mental health components in programs and policies targeting adolescent girls -given the high levels of vulnerability, especially in low-resource communities in SSA. Moreover, findings may point to the timing of screening and intervening for depressive symptoms among adolescents.

\section{Methods}

\section{Study sample}

This study utilized baseline data from the Suubi4Her study, a longitudinal randomized clinical trial (20172022), funded by the National Institute of Mental Health (Grant \# R01MH113486). A total of 1260 adolescent girls between 14 and 17 years of age at study initiation, were enrolled in the study. Adolescents were eligible to participate if they met the following inclusion criteria: 1) female, 2) age 14-17 years, 3) enrolled in the first year of secondary school, and 4) living within a family (broadly defined and not an institution or orphanage).

\section{Participant recruitment}

Adolescents were identified and recruited from $47 \mathrm{sec}-$ ondary schools in five geopolitical districts in southern Uganda. All schools in the study were matched based on socioeconomic status of the students attending these schools, school size (total number of students enrolled), location (urban vs. rural), and overall performance based on the Uganda Certificate of Education (UCE) examinations, administered by the Uganda Government's Ministry of Education and Sports. School administrators helped to identify potential participants and their parents/caregivers. Parents/caregivers were given flyers notifying them of the study and inviting them to contact the school headteacher for further details. In addition, community development officers and implementing partners distributed flyers during their frequent community visits to inform parents/caregivers whose children met the inclusion criteria but may not yet have reported to school. Caregivers and adolescents who expressed interest were later invited to meet with the in-country project coordinator for a one-on-one informational meeting. During the meeting, parents/caregivers and adolescents were informed verbally and in writing, the purpose of the study, voluntary participation, extent of their participation, risk and benefits, as well as protection and confidentiality issues. Interested caregivers/parents signed the informed consent and adolescent girls signed the assent forms. Detailed information on participants recruitment and selection process, power analysis, as well as the intervention is described in the study protocol and in our other publications $[75,76]$.

\section{Data collection and measures}

Detailed data collection procedures are provided elsewhere $[75,76]$. In brief, a 90-min interviewer -administered survey was utilized to collect data. Interviews were conducted in the Luganda local language by trained Uganda interviewers. All measures utilized in this study were tested in our previous studies in Uganda among children and adolescents affected by HIV/AIDS in the study area $[62-65,77,78]$.

\section{Outcome variable}

Depressive symptoms were measured using the Beck's Depression Inventory (BDI) [79]. The 21-item scale measures characteristic attitudes and symptoms of depression ranked based on severity $(0=$ least, $3=$ most $)$. Scores range from 0 to 63 (alpha $=0.83$ ), with higher scores indicating higher levels of depressive symptoms.

\section{Measures of psychological wellbeing}

Self-concept was measured using the Tennessee SelfConcept Scale [80]. The 20-item scale measures children's perception of identity and self-satisfaction $(1=\mathrm{al}-$ ways false and $5=$ always true). The scale ranges from 20 to 100 (alpha $=0.83$ ), with higher scores indicating higher levels of child self-concept. Participants' self-esteem was measured using the Rosenberg Self-Esteem Scale [81]. The 10-item scale measures individual selfesteem $(1=$ strongly disagree to $4=$ strongly agree $)$. Scores range from 10 to 40 (alpha $=0.66$ ), with higher scores indicating high levels of self-esteem. Hopelessness was measured using the Beck Hopelessness Scale [82]. The 20-item scale measures children's hopelessness and pessimistic attitudes toward the future $(1=$ true and $0=$ false). Scores range from 0 to 20 (alpha $=0.71$ ), with higher scores indicating higher level of hopelessness and pessimistic attitudes.

\section{Family and social support factors}

Family cohesion was measured using 7 items that assess family members' commitment and support for each other $(1=$ never and $5=$ always $)[83,84]$. Scores range from 7 to 35 (Cronbach alpha $=0.72$ ), with high scores indicating higher levels of family cohesion. Participants' perceived caregiver support was assessed using 17 items adapted from the Social Support Behaviors Scale (SS-B) scale $(1=$ never and $5=$ always $)$ [85]. Scores range from 17 to 85 (alpha $=0.78$ ), with high scores indicating high 
levels of perceived support from caregivers. Family care and relationship was measured using 6 items related to things that parents sometimes do with their children ( $1=$ never and $5=$ always). Scores ranges from 6 to 30 (alpha $=0.60)$, with higher scores indicating higher levels of family care and relationships. Social support from multiple sources was measured using 30 items adapted from the Friendship Qualities Scale [86]. Items assess the impressions of the quality of children's friendships and relationships $(1=$ never and $5=$ always $)$. Scores range from 30 to 150 (alpha $=0.81$ ), with high scores indicating higher levels of social support and relationships.

Finally, participant's sociodemographic and household characteristics included in the analysis as covariates were: 1) participants' age categorized into 14-15 years versus 16-17 years, 2) orphanhood status, 3) primary caregiver, 4) household size, and 5) household assets.

\section{Data analysis procedures}

We analyzed sociodemographic and household characteristics of the sample, followed by bivariate analyses of predictors of depressive symptoms (sociodemographic and household characteristics, family and social support factors and psychological wellbeing) across participants' age groups. We estimated the chi- square or t-test values for each of the variables. To address research questions 1 and 2 (i.e. determine the prevalence of depressive symptoms and variation by age groups), BDI scores were divided into 4 categories based on the scoring guidelines in non-clinical populations [87], minimal (0-9), mild (10-18) moderate (19-29) and severe (30+) symptoms. We then conducted chi square tests by age groups i.e., younger adolescents (14-15 years) versus older adolescents (16-17 years). Older adolescents tend to have high levels of depressive symptoms compared to young ones $[10,11]$. To address research question 3 , a summated score of the BDI scale was created. Hierarchical regression models were conducted to determine the predictors of depressive symptoms. We used the Variation Inflation Factor (VIF) to check for multicollinearity of the predictors and all the mean values were less than 5 . We conducted three models, with each model controlling for a block of predictors. Model 1 controlled for sociodemographics and household characteristics; model 2 controlled for family and social support factors, and model 3 controlled for psychological wellbeing. We compared the adjusted $\mathrm{R}$ squares to determine the strength of each model. Data was analyzed in STATA version 15.

\section{Results}

Sample characteristics

Baseline sample characteristics are presented in Table 1 below. The average age of participants is 15.4 years, with
Table 1 Sample Characteristics

\begin{tabular}{ll}
\hline Variable & $\begin{array}{l}\text { Total Sample }(\boldsymbol{N}=\mathbf{1 2 6 0}) \\
\%(\boldsymbol{n})\end{array}$ \\
\hline Age & $56.98(718)$ \\
14 to 15 years & $43.02(542)$ \\
16 to 17 years & \\
Orphan hood Status & $17.06(215)$ \\
Orphan & $82.94(1045)$ \\
Non - orphan & \\
Primary Caregiver & $76.59(965)$ \\
Biological parent & $11.11(140)$ \\
Grandparent & $12.30(155)$ \\
Other relative & \\
Household size (Mean, SD) & $7.00(2.71)$ \\
Number of people in HH & $3.49(2.10)$ \\
Number of children in HH & $11.46(3.26)$ \\
Family Assets (Mean, SD)
\end{tabular}

the majority of participants (57\%) between 14 and 15 years. About $83 \%$ of participants are non-orphan, and $76.6 \%$ identified a biological parent as their primary caregiver. The average household is 7 people, with three children under the age of 18 years living in the household. The average score on family asset index (including land, modes of transportation and communication, gardens, farm animals and small business) is 11.46 out of the expected 21, indicating moderate levels of asset ownership.

\section{Participants' sociodemographic and household characteristics, family and social support factors and psychological wellbeing, by age group}

Results from bivariate analyses for participants' sociodemographic and household characteristics, family support, social support factors and psychological wellbeing by age groups are presented in Table 2. Participants in both age groups were similar in terms of orphanhood status and primary caregiver reports. Older adolescents were more likely to report on average, slightly more children living in the household compared to younger adolescents (3.64 versus 3.39 children). The mean difference between the two age groups was statistically significant $(t=-2.02$, $p \leq .05)$. In terms of social support factors, younger adolescents reported slightly higher scores on all measures of family and social support factors compared to older adolescents, including on family cohesion ( mean $=26.61$ versus 26.53), family care and relationships (mean = 25.28 versus 24.01 ) and perceived child-caregiver support (mean $=57.16$ versus 56.44 ). The mean score difference on the measure of family care and relationship was statistically significant $(t=5.27, p=.001)$. In addition, 
Table 2 Bivariate Analysis Results: Sociodemographic and household characteristics, family and social support factors, and participants' psychological wellbeing by age groups

\begin{tabular}{|c|c|c|c|c|}
\hline Variable & $\begin{array}{l}\text { Total Sample } \\
(N=1260) \\
\text { Mean (SD) }\end{array}$ & $\begin{array}{l}14-15 \text { years } \\
(n=718) \\
\text { Mean (SD) }\end{array}$ & $\begin{array}{l}16-17 \text { years } \\
(n=542) \\
\text { Mean (SD) }\end{array}$ & $x^{2} /$ t-test \\
\hline \multicolumn{5}{|l|}{ Orphan hood Status $(\%, n)$} \\
\hline Orphan & $17.06(215)$ & $17.27(124)$ & $16.79(91)$ & \multirow[t]{2}{*}{0.05} \\
\hline Non - orphan & $82.94(1045)$ & $82.72(594)$ & $83.21(451)$ & \\
\hline \multicolumn{5}{|l|}{ Primary Caregiver $(\%, n)$} \\
\hline Biological parent & $76.59(965)$ & $75.91(545)$ & $77.49(420)$ & \multirow[t]{3}{*}{1.88} \\
\hline Grandparent & $11.11(140)$ & $10.72(77)$ & $11.62(63)$ & \\
\hline Other relative & $12.30(155)$ & $13.37(96)$ & $10.89(59)$ & \\
\hline \multicolumn{5}{|l|}{ Household size } \\
\hline Number of people in $\mathrm{HH}$ (min/max: 2-31) & $7.00(2.71)$ & $6.88(2.78)$ & $7.16(6.94)$ & -1.81 \\
\hline Number of children in $\mathrm{HH}$ (min/max: 0-13) & $3.49(2.10)$ & $3.39(2.01)$ & $3.64(3.45)$ & $-2.02^{*}$ \\
\hline Family assets (min/max: 0-20) & $11.46(3.26)$ & $11.32(3.29)$ & $11.64(3.21)$ & -1.71 \\
\hline \multicolumn{5}{|l|}{ Family support factors } \\
\hline Family cohesion (min/max:7-35) & $26.58(5.69)$ & $26.61(5.73)$ & $26.53(5.66)$ & 0.25 \\
\hline Family care and relationship (min/max: 9-30) & $24.74(4.27)$ & $25.28(4.09)$ & $24.01(4.41)$ & $5.27^{* * *}$ \\
\hline Perceived child-caregiver support ( $\min / \max : 29-81$ ) & $56.85(6.73)$ & $57.16(6.72)$ & $56.44(6.72)$ & 1.85 \\
\hline \multicolumn{5}{|l|}{ Social support from multiple sources } \\
\hline Guardian (min/max: 9-30) & $23.66(4.19)$ & $23.93(4.12)$ & $23.29(4.25)$ & $2.67^{* *}$ \\
\hline Classmate (min/max: 7-25) & $17.78(3.52)$ & $17.87(3.55)$ & $17.67(3.47)$ & 1.01 \\
\hline Teacher (min/max:10-30) & $22.85(4.23)$ & $23.11(4.22)$ & $22.49(4.21)$ & $2.58^{* *}$ \\
\hline Friend/peer (min/max: 26-65) & $51.63(7.61)$ & $51.91(7.51)$ & $51.27(7.74)$ & 1.48 \\
\hline \multicolumn{5}{|l|}{ Psychological wellbeing } \\
\hline Tennessee Self - Concept (min/max: 44-100) & $80.84(11.98)$ & $81.79(11.75)$ & $79.58(12.17)$ & $3.26^{* * *}$ \\
\hline Beck's Hopelessness Scale (min/max: 0-16) & $4.20(2.97)$ & $3.96(2.90)$ & $4.53(3.04)$ & $-3.41^{* * *}$ \\
\hline Rosenberg Self Esteem Scale (min/max: 16-40) & $34.00(4.57)$ & $34.20(4.53)$ & $33.75(4.63)$ & 1.62 \\
\hline
\end{tabular}

younger adolescents were more likely to report slightly higher scores on social support from parents/guardians $(t=2.67, p \leq .01)$ and from teachers $(t=2.58, p \leq .01)$ compared to older adolescent. Similar results were observed on measures of psychological wellbeing. Specifically, younger adolescents reported slightly higher scores on self-concept (mean $=81.79$ versus 79.58 ) and selfesteem (mean $=34.20$ versus 33.75 ), and lower scores on measures of hopelessness (mean $=3.96$ versus 4.53 ). The mean score difference between the two age groups for both self-concept $(t=3.26, p=.001)$ and hopelessness $(t=-3.41, p=.001)$ were statistically significant.

\section{Prevalence of depressive symptoms}

As presented in Table 3, scores on the BDI scale were divided into four levels of depressive symptoms (minimal, mild, moderate and severe symptoms). In our sample, over one third (31.83\%) of participants reported

Table 3 Prevalence of Depressive Symptoms Across Age groups

\begin{tabular}{llll}
\hline Depressive Symptoms & $\begin{array}{l}\text { Total Sample }(\boldsymbol{N}=\mathbf{1 2 6 0}) \\
\%(\mathbf{n})\end{array}$ & $\begin{array}{l}\text { Younger Adolescents: } \\
\mathbf{1 4 - 1 5} \text { years } \\
(\boldsymbol{n}=\mathbf{7 1 8}) \text { \%(n) }\end{array}$ & $\begin{array}{l}\text { Older Adolescents: 16-17 years } \\
(\boldsymbol{n}=\mathbf{5 4 2}) \%(\mathbf{n})\end{array}$ \\
\hline Minimal & $22.14(279)$ & $22.70(163)$ & $21.40(116)$ \\
Mild & $31.83(401)$ & $34.68(249)$ & $28.04(152)$ \\
Moderate & $29.68(374)$ & $27.16(195)$ & $33.03(179)$ \\
Severe & $16.35(206)$ & $15.46(111)$ & $17.53(95)$ \\
\hline
\end{tabular}


mild symptoms, 29.68\% reported moderate symptoms and $16.35 \%$ reported severe symptoms. Within age groups, more younger adolescents than older adolescents reported minimal depressive symptoms (22.7\% versus $21.4 \%$ ) and mild symptoms (34.68\% versus $28.04 \%$ ). On the other hand, more older adolescents than younger adolescents reported moderate (33.03\% versus $27.16 \%)$ and severe symptoms (17.53\% versus $15.46 \%)$.

\section{Predictors of depressive symptoms}

Results from hierarchical regression analyses are presented in Table 4. Predictors were entered into the model as a block of predictors. In model 1 , we control for participants' sociodemographic and household characteristics (age, orphanhood type, primary caregivers, household size and family assets). In model 2 we add family and social support factors (family cohesion, family and care relationship, perceived child-caregiver support and social support from multiple sources). In model 3 we add measures of psychological wellbeing (self-concept, self-esteem and hopelessness). Age, orphanhood status and family assets were associated with depressive symptoms. Specifically, being an older adolescent girl (16-17 years) was associated with higher levels of depressive symptoms $(B=1.15,95 \%$ $\mathrm{CI}=0.02,2.28, p \leq .05)$. On the other hand, having both parents alive, i.e. non-orphaned adolescent $(B=-1.99,95 \%$ $\mathrm{CI}=-3.56,-0.429, p \leq .01)$ and higher levels of family

Table 4 Regression on sociodemographic and household characteristics, family and social support factors, psychological wellbeing

\begin{tabular}{|c|c|c|c|}
\hline Variable & $\begin{array}{l}\text { Model 1: } \\
\text { B }(95 \% \mathrm{Cl}) \\
\end{array}$ & $\begin{array}{l}\text { Model 2: } \\
\text { B (95\%Cl) }\end{array}$ & $\begin{array}{l}\text { Model 3: } \\
\text { B (95\%Cl) } \\
\end{array}$ \\
\hline \multicolumn{4}{|l|}{ Sociodemographic and Household characteristics } \\
\hline \multicolumn{4}{|l|}{ Age: (ref: 14 to 15 years) } \\
\hline 16 to 17 years & $1.15(0.02,2.28) *$ & $0.07(-0.96,1.09)$ & $-0.43(-1.41,0.55)$ \\
\hline \multicolumn{4}{|l|}{ Orphan hood Status: (ref: Orphan) } \\
\hline Non-orphan & $-1.99(-3.56,-0.429) * *$ & $-1.32(-2.73,0.09)$ & $-0.89(-2.24,0.45)$ \\
\hline \multicolumn{4}{|l|}{ Primary Caregiver: (ref: Biological parent) } \\
\hline Grandparent & $0.59(-1.23,2.42)$ & $0.27(-1.36,1.91)$ & $0.48(-1.05,2.02)$ \\
\hline Other relative & $-0.21(-2.01,1.59)$ & $-0.41(-2.02,1.21)$ & $-0.39(-1.90,1.13)$ \\
\hline \multicolumn{4}{|l|}{ Household size } \\
\hline Number of people in $\mathrm{HH}$ & $0.29(-0.04,0.62)$ & $0.14(-0.16,0.43)$ & $0.09(-0.19,0.38)$ \\
\hline Number of children in $\mathrm{HH}$ & $0.01(-0.41,0.44)$ & $0.08(-0.29,0.46)$ & $0.01(-0.35,0.38)$ \\
\hline Family Assets & $-0.34(-0.51,-0.15)^{* * *}$ & $-0.14(-0.30,0.02)$ & $0.07(-0.08,0.23)$ \\
\hline \multicolumn{4}{|l|}{ Family and Social Support Factors } \\
\hline Family cohesion & & $-0.0003(-0.10,0.09)$ & $0.03(-0.07,0.12)$ \\
\hline Family care and relationship & & $-0.38(-0.51,-0.24) * * *$ & $-0.24(-0.37,-0.11) * * *$ \\
\hline Perceived Child and Caregiver support & & $-0.12(-0.19,-0.03) * *$ & $-0.04(-0.12,0.04)$ \\
\hline \multicolumn{4}{|l|}{ Social support from multiple sources } \\
\hline Guardian & & $-0.31(-0.46,-0.17)^{* * *}$ & $-0.16(-0.29,-0.016) *$ \\
\hline Classmate & & $-0.14(-.30,0.03)$ & $-0.02(-0.18,0.14)$ \\
\hline Teacher & & $-0.13(-0.28,0.01)$ & $0.08(-0.06,0.22)$ \\
\hline Friend/peer & & $-0.27(-0.35,-0.19) * * *$ & $-0.12(-0.19,-0.04) * *$ \\
\hline \multicolumn{4}{|l|}{ Psychological wellbeing } \\
\hline Tennessee Self - Concept & & & $-0.28(-0.33,-0.22) * * *$ \\
\hline Beck's Hopelessness Scale & & & $0.56(0.35,0.77)^{* * *}$ \\
\hline Rosenberg Self Esteem Scale & & & $-0.21(-0.33,-0.09) * * *$ \\
\hline The F-value & $4.38^{* * *}$ & $25.67^{* * *}$ & $35.37^{* * *}$ \\
\hline$R^{2}$ & 0.024 & 0.224 & 0.356 \\
\hline Adjusted R²(df) & $0.02(7)$ & $0.22(14)$ & $0.35(17)$ \\
\hline Change in $R^{2}$ & & $0.200^{* * *}$ & $0.132^{* * *}$ \\
\hline N & 1260 & 1260 & 1106 \\
\hline
\end{tabular}

${ }^{*} p \leq .05 ;{ }^{* *} p \leq .01 ;{ }^{* * *} p \leq .001$ 
assets $(\mathrm{B}=-0.34,95 \% \mathrm{CI}=-0.51,-0.15, p=.001)$ were both associated with lower levels of depressive symptoms.

When we added family and social support factors in model 2, age, orphanhood status and family assets became non-significant. Family care and relationship ( $\mathrm{B}=$ $-0.38,95 \% \mathrm{CI}=-0.51, \quad-0.24, p=.001)$, perceived child-caregiver support $(B=-0.12,95 \% C I=-0.19$, $0.03, p \leq .01)$, social support from a parent/caregiver $(\mathrm{B}=-0.31,95 \% \mathrm{CI}=-0.46,-0.17, p=.001)$, and social support from a friend/peer $(B=-0.27,95 \% C I=-0.35$, $-0.19, p=.001)$ were all associated with lower levels of depressive symptoms among adolescent girls.

Finally, controlling for measures of psychological wellbeing (model 3$)$, family care and relationship $(\mathrm{B}=-0.24$, $95 \% \mathrm{CI}=-0.37,-0.11, p=.001)$, social support from the parent/caregiver $(B=-0.16,95 \% C I=-0.29$, $0.016, p \leq .05)$, social support from the peer/friend ( $\mathrm{B}=$ $-0.12,95 \% \mathrm{CI}=-0.19,-0.04, p \leq .01)$ remained significant predictors of lower depressive symptoms. In addition, while self-concept $(\mathrm{B}=-0.28,95 \% \mathrm{CI}=-0.33$, $-0.22, p=.001)$ and self-esteem $(\mathrm{B}=-0.21,95 \% \mathrm{CI}$ : $0.33,-0.09, p=.001)$ were both associated with lower levels of depressive symptoms, feelings of hopelessness were associated with higher levels of depressive symptoms $(\mathrm{B}=0.56,95 \% \mathrm{CI}=0.35,0.77, p=.001)$.

The model containing sociodemographic and household characteristics accounted for $2.4 \%\left(\mathrm{R}^{2}=.024\right)$ of the variance in depressive symptoms. When we added family and social support factors (model 2), we are able to explain $22.4 \%\left(\mathrm{R}^{2}=.224\right)$ of the variance. The 20percentage change between model 1 and model 2 was statistically significant $(p=.001)$. Adding measures of psychological wellbeing (model 3 ) allowed us to explain $35.6 \%$ of the variance in depressive symptoms $\left(\mathrm{R}^{2}=\right.$ .356). The 13.2 percentage change between model 2 and model 3 was statistically significant $(\mathrm{p}=.001)$.

\section{Discussion}

This study utilized baseline data to estimate the prevalence and predictors of depressive symptoms among high school adolescent girls in Uganda. Our findings contribute to the limited literature estimating the prevalence of depressive symptoms-a growing public health concern among adolescents, especially those in low-income countries in SSA. In our sample, the prevalence rates ranged between 16 and $29 \%$ (moderate to severe depressive symptoms) and were more pronounced among adolescents 16 years and older. This finding is consistent with previous studies indicating that the severity of mental health disorders, including depressive symptoms continue to rise as children transition through adolescence and into young adulthood [10-12]. The prevalence rates in our sample are consistent with the prevalence rates reported in other studies conducted among high school adolescents in Uganda [73], and indicate high prevalence with significant health, mental health and social implications for adolescents. In particular, adolescents with severe symptoms are at a higher risk of developing later depression [88-90] and other mental health disorders, behavioral health issues, including sexual risk-taking behaviors [31, 91, 92], and poor educational outcomes $[93,94]$. Taken together, these findings point to the need for early screening and detection of depressive symptoms to facilitate timely referral to treatment services.

In addition to adolescents' age, orphanhood status and household assets were associated with depressive symptoms. Although the significance of these two predictors disappear when social support factors are added into the model - signifying possible mediation, these findings are worth discussion. Specifically, having both parents alive was associated with lower levels of depressive symptoms -in an ideal supportive environment, this points to protective role of both parents against depressive symptoms [95]. Indeed, compared to nonorphans, orphaned adolescents are more likely to report poor mental health outcomes, mainly due to psychological distress surrounding parental death, stigma and discrimination associated with orphanhood, financial constraints, and the lack of social support from both within the household and the community [96-100]. On the other hand, possession of family assets (such as land, modes of transportation and communication, gardens, farm animals and small business) was associated with lower levels of depressive symptoms. This finding is consistent with findings from our previous studies that document the positive effects of assets and asset accumulation on adolescents' depression and overall mental health functioning [60, 63, 65, $101,102]$-pointing to the need for incorporating economic strengthening components in programming for vulnerable adolescents and youth in SSA.

Family and social support factors, including family care and relationships, perceived child-caregiver support, as well as support from caregivers and peers were all associated with lower levels of depressive symptoms among adolescent girls. This finding underscores the role of supportive relationships, especially from family members and peers as protective factors against depressive symptoms [47-50, 67, 103]. However, in our sample, family cohesion was not associated with depressive symptoms. It could be that family closeness alone is not enough to help address adolescents' depressive symptoms. As such, other supportive strategies to enable adolescents deal with stressful situations as they transition through adolescence, including developing trusting relationships, respectful and open child-caregiver communication, may be important. Indeed, one of the intervention components of the study focuses on strengthening family relationships to address mental health challenges and sexual risk-taking behaviors among adolescent girls [75]. We 
hope that analysis of post intervention data will reveal significant improvements, not only in family functioning, but also in the overall mental health functioning of study participants.

Finally, adolescents' psychological wellbeing, including self-esteem, self-concept, as well as lower levels of hopelessness, were all associated with low levels of depressive symptoms. Indeed, the model controlling for these measures explained the greatest variance in depressive symptoms. Consistent with other studies conducted elsewhere [38-42], it is critical to develop and/or strengthen these mechanisms among adolescents earlier on to build resilience and lessen the impact of risk factors associated with depressive symptoms and facilitate a smooth transition through adolescence.

\section{Limitations}

These findings should be carefully interpreted in light of the following limitations. First, the Beck Depression Inventory serves only as a screening tool for depressive symptoms. Scores are not meant to be interpreted as a diagnosis -as this requires further assessment. Second, we utilized data from one group- adolescent girls without a comparable group of adolescents. However, we do know from prior literature that the prevalence of depressive symptoms tend to be higher among adolescent girls and women compared to adolescent boys and men. Third, adolescents' age range was not broad enough to deduce robust gender differences. Fourth, all data was selfreported by adolescents -which may suffer from social desirability. Finally, we report baseline data only and are unable to make any causal inferences. Given that the study is still in the intervention implementation phase, post intervention data will be analyzed in the near future.

\section{Conclusions}

Study findings contribute to the limited literature estimating the prevalence and correlates of depressive symptoms among adolescent girls in low resource settings in Uganda. We find high prevalence rates of depressive symptoms, ranging between 16 and 29\%, and more pronounced among adolescents 16 years and older. These high rates point to the higher risk of developing later depression, if not addressed. Given that depressive symptoms tend to increase during later adolescence, our findings point to the need for early screening and detection to facilitate timely referral to support and treatment services. Family support factors and adolescents' psychological wellbeing were associated with low levels of depressive symptoms. These findings may inform the development and incorporation of gender-specific mental health components -especially those that target family support, economic strengthening, as well as psychological wellbeing among adolescents, living in low-resource communities in SSA.

\section{Abbreviations}

SSA: Sub-Saharan Africa; UCE: Uganda Certificate of Education;

CITI: Collaborative Institutional Training Initiative; BDI: Beck's Depression Inventory; RSES: Rosenberg Self-Esteem Scale; BHS: Beck Hopelessness Scale; TSCS: Tennessee Self-Concept Scale

\section{Acknowledgments}

The authors are grateful to the staff and the volunteer team at the International Center for Child Health and Development (ICHAD) field offices in Masaka- Uganda for monitoring the study implementation process. We are grateful to our implementing partners -Reach the Youth (RTY) Uganda, and Rakai Heath Sciences Program (RHSP), and Masaka Diocese - our collaborating partner in the region. Our special thanks go to all children and their caregiving families who agreed to participate in the study.

\section{Authors' contributions}

PN wrote the manuscript. CD managed the study data and led the data analysis process. FMS wrote the grant and obtained funding for the study. FN coordinated the study. WB, JM, RB, EI, WT, OSB and FMS reviewed the manuscript for intellectual content and made significant additions to the manuscript. All authors read and approved the final manuscript.

\section{Funding}

The Suubi4Her study was funded by the National Institute of Mental Health (NIMH Grant \# R01MH113486; PI: Fred M. Ssewamala). NIMH had no role in the study design, data collection, analysis, interpretation of findings and preparing this manuscript. The content of this paper is solely the responsibility of the authors and does not necessarily represent the official views of the $\mathrm{NIMH}$ or $\mathrm{NIH}$

\section{Availability of data and materials}

The datasets analyzed during the current study are available from the corresponding author on reasonable request.

\section{Ethics approval and consent to participate}

Participation in the Suubi4Her study was voluntary. All caregivers provided written consent for their children to participate in the study. Similarly, all adolescent girls provided written assent to participate. This was obtained separately from their caregivers to avoid coercion. The study received Institutional Review Board approval from Washington University in St. Louis (IRB- \#201703102), the Uganda Virus Research Institute (GC/127/17/07/619), and the Uganda National Council of Science and Technology (SS4406). The study is registered in the Clinical Trials database (NCT03307226).

\section{Consent for publication}

Not Applicable.

\section{Competing interests}

The authors declare that they have no competing interests.

Received: 13 April 2020 Accepted: 19 November 2020

Published online: 25 November 2020

\section{References}

1. World Health Organization. Adolescent mental health. 2019. Accessed on 27 Feb 2020 from: https://www.who.int/news-room/fact-sheets/detail/ adolescent-mental-health.

2. Lopez AD, Mathers CD, Ezzati M, Jamison DT, Murray CJ. Global and regional burden of disease and risk factors, 2001: systematic analysis of population health data. Lancet. 2006;367(9524):1747-57.

3. Cortina MA, Sodha A, Fazel M, Ramchandani PG. Prevalence of child mental health problems in sub-Saharan Africa: a systematic review. Archives Pediatrics Adolescent Med. 2012;166(3):276-81.

4. Nduna M, Jewkes RK, Dunkle KL, Jama Shai NP, Colman I. Prevalence and factors associated with depressive symptoms among young women and men in the eastern Cape Province, South Africa. J Child Adolesc Ment Health. 2013;25(1):43-54.

5. Crabb J, Stewart RC, Kokota D, Masson N, Chabunya S, Krishnadas R. Attitudes towards mental illness in Malawi: a cross-sectional survey. BMC Public Health. 2012;12(1):541. 
6. Hugo CJ, Boshoff DE, Traut A, Zungu-Dirwayi N, Stein DJ. Community attitudes toward and knowledge of mental illness in South Africa. Soc Psychiatry Psychiatr Epidemiol. 2003;38(12):715-9.

7. Atilola O, Balhara YP, Stevanovic D, Avicenna M, Kandemir H. Self-reported mental health problems among adolescents in developing countries: results from an international pilot sample. J Dev Behav Pediatrics. 2013;34(2):129-37.

8. Kariuki SM, Abubakar A, Kombe M, Kazungu M, Odhiambo R, Stein A, Newton CR. Burden, risk factors, and comorbidities of behavioural and emotional problems in Kenyan children: a population-based study. Lancet Psychiatry. 2017;4(2):136-45.

9. Owen JP, Baig B, Abbo C, Baheretibeb Y. Child and adolescent mental health in sub-Saharan Africa: a perspective from clinicians and researchers. BJPsych international. 2016;13(2):45-7.

10. Giaconia RM, Reinherz HZ, Silverman AB, Pakiz B, Frost AK, Cohen E. Ages of onset of psychiatric disorders in a community population of older adolescents. J Am Acad Child Adolesc Psychiatry. 1994;33(5):706-17.

11. Hankin BL, Abramson LY, Moffitt TE, Silva PA, McGee R, Angell KE. Development of depression from preadolescence to young adulthood: emerging gender differences in a 10-year longitudinal study. J Abnorm Psychol. 1998;107(1):128.

12. Kieling C, Baker-Henningham H, Belfer M, Conti G, Ertem I, Omigbodun O, Rohde LA, Srinath S, Ulkuer N, Rahman A. Child and adolescent mental health worldwide: evidence for action. Lancet. 2011;378(9801):1515-25.

13. Kessler RC, Angermeyer M, Anthony JC, De Graaf RO, Demyttenaere K, Gasquet I, De Girolamo G, Gluzman S, Gureje OY, Haro JM, Kawakami N. Lifetime prevalence and age-of-onset distributions of mental disorders in the World Health Organization's world mental health survey initiative. World Psychiatry. 2007;6(3):168.

14. Kapphahn CJ, Morreale MC, Rickert VI, Walker LR. Financing mental health services for adolescents: a position paper of the Society for Adolescent Medicine. J Adolesc Health. 2006 Sep 1;39(3):456-8.

15. Allgood-Merten B, Lewinsohn PM, Hops H. Sex differences and adolescent depression. J Abnorm Psychol. 1990;99(1):55-63.

16. Burke RJ, Weir T. Sex differences in adolescent life stress, social support, and well-being. J Psychol. 1978;98(2):277-88.

17. Nolen-Hoeksema S. Gender differences in depression. Curr Dir Psychol Sci. 2001;10(5):173-6.

18. Schraedley PK, Gotlib IH, Hayward C. Gender differences in correlates of depressive symptoms in adolescents. J Adolesc Health. 1999;25(2):98-108.

19. World Health Organization. Health for the World's Adolescents: A second chance in the second decade. 2014. https://www.who.int/maternal_child_ adolescent/documents/second-decade/en/. Accessed 27 Feb 2020.

20. Kapungu C, Petroni S. Understanding and tackling the gendered drivers of poor adolescent mental health. International Center for Research on Women. 2020, from: https://www.icrw.org/wp-content/uploads/2017/09/ ICRW_Unicef_MentalHealth_WhitePaper_FINAL.pdf.

21. Petroni S, Patel V, Patton G. Why is suicide the leading killer of older adolescent girls? Lancet. 2015;386(10008):2031-2.

22. Viner RM, Ozer EM, Denny S, Marmot M, Resnick M, Fatusi A, Currie C. Adolescence and the social determinants of health. Lancet. 2012;379(9826): $1641-52$.

23. Albert PR. Why is depression more prevalent in women? J Psychiatry Neurosci. 2015:40(4):219.

24. Patton GC, Sawyer SM, Santelli JS, Ross DA, Afifi R, Allen NB, Arora M, Azzopardi P. Baldwin W. Bonell C, Kakuma R. Our future: a lancet commission on adolescent health and wellbeing. Lancet. 2016;387(10036):2423-78.

25. Beck AT. Depression: clinical, experimental, and theoretical aspects: Hoeber Medical Division, Harper \& Row; 1967.

26. Beck JS, Beck AT. Cognitive therapy: basics and beyond. New York: Guilford press; 1995.

27. Beck AT. Cognitive therapy and the emotional disorders. Penguin; 1979

28. Johnson NI, Barrett R, Horricks L, Akintan O, Van Blyderveen S. Adolescent mental health and risky sexual behavior: a Canadian perspective. J Adolesc Health. 2014;54(2):S49.

29. Murphey D, Barry M, Vaughn B, Guzman L, Terzian M. Adolescent health highlight: use of illicit drugs. Trends Child. 2013; Accessed on 27 Feb 2020 from: https://www.childtrends.org/wp-content/uploads/2013/09/Illicit-druguse-Highlight-9.13.pdf.

30. Anatale K, Kelly S. Factors influencing adolescent girls' sexual behavior: a secondary analysis of the 2011 youth risk behavior survey. Issues Mental Health Nurs. 2015;36(3):217-21.
31. Lehrer JA, Shrier LA, Gortmaker S, Buka S. Depressive symptoms as a longitudinal predictor of sexual risk behaviors among US middle and high school students. Pediatrics. 2006;118(1):189-200.

32. Seth P, Patel SN, Sales JM, DiClemente RJ, Wingood GM, Rose ES. The impact of depressive symptomatology on risky sexual behavior and sexual communication among African American female adolescents. Psychol Health Med. 2011;16(3):346-56.

33. Goin DE, Pearson RM, Craske MG, Stein A, Pettifor A, Lippman SA, Kahn K, Neilands TB, Hamilton EL, Selin A, MacPhail C. Depression and Incident HIV in Adolescent Girls and Young Women in HIV Prevention Trials Network 068: Targets for Prevention and Mediating Factors. Am J Epidemiol. 2020; 189(5):422-32.

34. Babore A, Trumello C, Candelori C, Paciello M, Cerniglia L. Depressive symptoms, self-esteem and perceived parent-child relationship in early adolescence. Front Psychol. 2016;7:982.

35. Battle J. Relationship between self-esteem and depression among high school students. Percept Mot Skills. 1980;51(1):157-8.

36. Orth $U$, Robins RW. Understanding the link between low self-esteem and depression. Curr Dir Psychol Sci. 2013;22(6):455-60.

37. Sowislo JF, Orth U. Does low self-esteem predict depression and anxiety? A meta-analysis of longitudinal studies. Psychol Bull. 2013;139(1):213.

38. Steiger AE, Allemand M, Robins RW, Fend HA. Low and decreasing selfesteem during adolescence predict adult depression two decades later. J Pers Soc Psychol. 2014;106(2):325

39. Masselink M, Van Roekel E, Oldehinkel AJ. Self-esteem in early adolescence as predictor of depressive symptoms in late adolescence and early adulthood: the mediating role of motivational and social factors. Journal of youth and adolescence. 2018;47(5):932-46.

40. Rieger S, Göllner R, Trautwein U, Roberts BW. Low self-esteem prospectively predicts depression in the transition to young adulthood: a replication of Orth, Robins, and Roberts (2008). J Pers Soc Psychol. 2016;110(1):e16.

41. Cunningham S, Gunn T, Alladin A, Cawthorpe D. Anxiety, depression and hopelessness in adolescents: a structural equation model. J Can Acad Child Adolesc Psychiatry. 2008;17(3):137.

42. Greene SM. The relationship between depression and hopelessness: implications for current theories of depression. Br J Psychiatry. 1989;154(5): 650-9.

43. Almedom AM. Social capital and mental health: an interdisciplinary review of primary evidence. Soc Sci Med. 2005;61(5):943-64.

44. De Silva MJ, Huttly SR, Harpham T, Kenward MG. Social capital and mental health: a comparative analysis of four low income countries. Soc Sci Med. 2007;64(1):5-20.

45. Flores EC, Fuhr DC, Bayer AM, Lescano AG, Thorogood N, Simms V. Mental health impact of social capital interventions: a systematic review. Soc Psychiatry Psychiatr Epidemiol. 2018 Feb 1;53(2):107-19.

46. McPherson KE, Kerr S, McGee E, Morgan A, Cheater FM, McLean J, Egan J. The association between social capital and mental health and behavioural problems in children and adolescents: an integrative systematic review. BMC psychology. 2014;2(1):7.

47. Boudreault-Bouchard AM, Dion J, Hains J, Vandermeerschen J, Laberge L, Perron M. Impact of parental emotional support and coercive control on adolescents' self-esteem and psychological distress: results of a four-year longitudinal study. J Adolesc. 2013;36(4):695-704.

48. Gariepy G, Honkaniemi H, Quesnel-Vallee A. Social support and protection from depression: systematic review of current findings in Western countries. Br J Psychiatry. 2016;209(4):284-93.

49. Holahan CJ, Valentiner DP, Moos RH. Parental support, coping strategies, and psychological adjustment: an integrative model with late adolescents. J Youth Adolescence. 1995;24(6):633-48.

50. Cheng Y, Li X, Lou C, Sonenstein FL, Kalamar A, Jejeebhoy S, DelanyMoretlwe $\mathrm{S}$, Brahmbhatt $\mathrm{H}$, Olumide $\mathrm{AO}$, Ojengbede $\mathrm{O}$. The association between social support and mental health among vulnerable adolescents in five cities: findings from the study of the well-being of adolescents in vulnerable environments. J Adolesc Health. 2014;55(6):S31-8.

51. Delsing MJ, Van Aken MA, Oud JH, De Bruyn EE, Scholte RH. Family loyalty and adolescent problem behavior: the validity of the family group effect. J Res Adolesc. 2005;15(2):127-50.

52. Fulkerson JA, Story M, Mellin A, Leffert N, Neumark-Sztainer D, French SA. Family dinner meal frequency and adolescent development: relationships with developmental assets and high-risk behaviors. J Adolesc Health. 2006; 39(3):337-45. 
53. Ying YW, Han M. Parental contributions to southeast Asian American adolescents' well-being. Youth Soc. 2008;40(2):289-306.

54. Arat G, Wong PW. The relationship between parental involvement and adolescent mental health in six sub-Saharan African countries: findings from global school-based health surveys (GSHS). Int J Ment Health Promot. 2016;18(3): 144-57.

55. Bireda AD, Pillay J. Perceived parental involvement and well-being among Ethiopian adolescents. J Psychol Afr. 2017;27(3):256-9.

56. Springer A, Parcel G, Baumler E, Ross M. Supportive social relationships and adolescent health risk behavior among secondary school students in El Salvador. Soc Sci Med. 2006;62(7):1628-40.

57. Yugo M, Davidson MJ. Connectedness within social contexts: the relation to adolescent health. Healthcare Policy. 2007;2(3):47.

58. Henry MB, Kitaka SB, Lubega K, Snyder SA, LaRussa P, Pfeffer B. Depressive symptoms, sexual activity, and substance use among adolescents in Kampala, Uganda. Afr Health Sci. 2019;19(2):1888-96.

59. Kyohangirwe L, Okello E, Namuli JD, Ndeezi G, Kinyanda E. Prevalence and factors associated with major depressive disorder among adolescents attending a primary care facility in Kampala. Uganda Tropical doctor. 2019;9: 0049475519879586.

60. Kivumbi A, Byansi W, Ssewamala FM, Proscovia N, Damulira C, Namatovu P. Utilizing a family-based economic strengthening intervention to improve mental health wellbeing among female adolescent orphans in Uganda. Child Adolesc Psychiatry Ment Health. 2019;13(1):14.

61. Musisi S, Kinyanda E, Nakasujja N, Nakigudde J. A comparison of the behavioral and emotional disorders of primary school-going orphans and nonorphans in Uganda. Afr Health Sci. 2007;7(4):202-13.

62. Ssewamala FM, Han CK, Neilands TB. Asset ownership and health and mental health functioning among AIDS-orphaned adolescents: findings from a randomized clinical trial in rural Uganda. Soc Sci Med. 2009;69(2): 191-8.

63. Ssewamala FM, Karimli L, Torsten N, Wang JS, Han CK, lic V, Nabunya P. Applying a family-level economic strengthening intervention to improve education and health-related outcomes of school-going AIDS-orphaned children: lessons from a randomized experiment in southern Uganda. Prev Sci. 2016;17(1):134-43.

64. Ssewamala FM, Nabunya P, Ilic V, Mukasa MN, Ddamulira C. Relationship between family economic resources, psychosocial well-being, and educational preferences of AIDS-orphaned children in southern Uganda: baseline findings. Global Social Welfare. 2015;2(2):75-86.

65. Ssewamala FM, Neilands TB, Waldfogel J, Ismayilova L. The impact of a comprehensive microfinance intervention on depression levels of AIDSorphaned children in Uganda. J Adolesc Health. 2012;50(4):346-52.

66. Akimana B, Abbo C, Balagadde-Kambugu J, Nakimuli-Mpungu E. Prevalence and factors associated with major depressive disorder in children and adolescents at the Uganda Cancer institute. BMC Cancer. 2019;19(1):466.

67. Cavazos-Rehg P, Xu C, Kasson E, Byansi W, Bahar OS, Ssewamala FM. Social and economic equity and family cohesion as potential protective factors from depression among adolescents living with HIV in Uganda. AIDS Behav. 2020;24:1-9.

68. Kemigisha E, Zanoni B, Bruce K, Menjivar R, Kadengye D, Atwine D, Rukundo GZ. Prevalence of depressive symptoms and associated factors among adolescents living with HIV/AIDS in South Western Uganda. AIDS Care. 2019;31(10):1297-303.

69. Kinyanda E, Hoskins S, Nakku J, Nawaz S, Patel V. The prevalence and characteristics of suicidality in HIV/AIDS as seen in an African population in Entebbe district, Uganda. BMC Psychiatry. 2012;12(1):63.

70. Musisi S, Kinyanda E. Emotional and behavioural disorders in HIV seropositive adolescents in urban Uganda. East Afr Med J. 2009;86(1):16-24.

71. Abbo C, Kinyanda E, Kizza RB, Levin J, Ndyanabangi S, Stein DJ. Prevalence, comorbidity and predictors of anxiety disorders in children and adolescents in rural North-Eastern Uganda. Child Adolesc Psychiatry Ment Health. 2013;7(1):21.

72. Okello J, Onen TS, Misisi S. Psychiatric disorders among war-abducted and non-abducted adolescents in Gulu district, Uganda: a comparative study. African J Psychiatry. 2007;10(4):225-31.

73. Nalugya-Sserunjogi J, Rukundo GZ, Ovuga E, Kiwuwa SM, Musisi S, NakimuliMpungu E. Prevalence and factors associated with depression symptoms among school-going adolescents in Central Uganda. Child Adolesc Psychiatry Ment Health. 2016;10(1):39.

74. Harandi TF, Taghinasab MM, Nayeri TD. The correlation of social support with mental health: a meta-analysis. Electron Physician. 2017;9(9):5212.
75. Ssewamala FM, Bermudez LG, Neilands TB, Mellins CA, McKay MM, Garfinkel I, Bahar OS, Nakigozi G, Mukasa M, Stark L, Damulira C. Suubi4Her: a study protocol to examine the impact and cost associated with a combination intervention to prevent HIV risk behavior and improve mental health functioning among adolescent girls in Uganda. BMC Public Health. 2018; 18(1):693.

76. Ssewamala FM, Nabunya P, Bahar OS, William B, Namuwonge F, Damulira C, Mukasa M, Ahmed R, Tumwesige W, Zmachinski L, Team IC. Suubi4Her: A Combination Intervention Addressing HIV Risk Among Older Adolescent Girls Transitioning into Adulthood in Uganda. 2019. Accessed on 25 Feb 2020, from: https://ichad.wustl.edu/wp-content/uploads/2019/12/Suubi4HerBaseline-Report_FINAL-1.pdf.

77. Damulira C, Mukasa MN, Byansi W, Nabunya P, Kivumbi A, Namatovu P, Namuwonge F, Dvalishvili D, Sensoy Bahar O, Ssewamala FM. Examining the relationship of social support and family cohesion on ART adherence among HIV-positive adolescents in southern Uganda: baseline findings. Vulnerable children and youth studies. 2019;14(2):181-90.

78. Karimli L, Ssewamala FM, Ismayilova L. Extended families and perceived caregiver support to AIDS orphans in Rakai district of Uganda. Child Youth Serv Rev. 2012;34(7):1351-8.

79. Beck AT, Ward CH, Mendelson M, Mock J, Erbaugh J. An inventory for measuring depression. Arch Gen Psychiatry. 1961;4(6):561-71.

80. Fitts WH, Warren WL. Tennessee self-concept scale: TSCS-2. Los Angeles: Western Psychological Services; 1996

81. Rosenberg M. Princeton University Press; Princeton, NJ: 1965. Society and the adolescent self-image. Accessed 20 Feb 2020, from: https://www. docdroid.net/Nt9xpBg/society-and-theadolescent-self-image-morrisrosenberg-1965.pdf.

82. Beck AT, Weissman A, Lester D, Trexler L. The measurement of pessimism: The Hopelessness Scale. J Consult Clin Psychol. 1974;42(6):861-5.

83. Moos RH. Family environment scale manual: Consulting Psychologists Press; 1994.

84. Skinner HA, Steinhauer PD, Santa-Barbara J. The family assessment measure. Can J Commun Mental Health. 2009;2(2):91-103.

85. Vaux A, Riedel S, Stewart D. Modes of social support: the social support behaviors (SS-B) scale. Am J Community Psychol. 1987;15(2):209-32.

86. Bukowski WM, Hoza B, Boivin M. Measuring friendship quality during preand early adolescence: the development and psychometric properties of the friendship qualities scale. J Soc Pers Relat. 1994;11(3):471-84.

87. Beck AT, Steer RA, Brown GK. Manual for the Beck Depression Inventory-II. San Antonio: Psychological Corporation; 1996.

88. Fergusson DM, Woodward $\sqcup$. Mental health, educational, and social role outcomes of adolescents with depression. Arch Gen Psychiatry. 2002;59(3):225-31.

89. Hale DR, Bevilacqua L, Viner RM. Adolescent health and adult education and employment: a systematic review. Pediatrics. 2015;136(1):128-40.

90. Lewinsohn PM, Rohde P, Klein DN, Seeley JR. Natural course of adolescent major depressive disorder: I. continuity into young adulthood. J Am Acad Child Adolesc Psychiatry. 1999;38(1):56-63.

91. Kosunen E, Kaltiala-Heino R, Rimpelä M, Laippala P. Risk-taking sexual behaviour and self-reported depression in middle adolescence-a schoolbased survey. Child Care Health Dev. 2003;29(5):337-44.

92. Thapar A, Collishaw S, Pine DS, Thapar AK. Depression in adolescence. Lancet. 2012;379(9820):1056-67.

93. Fletcher JM. Adolescent depression and educational attainment: results using sibling fixed effects. Health Econ. 2010;19(7):855-71.

94. McLeod JD, Uemura R, Rohrman S. Adolescent mental health, behavior problems, and academic achievement. J Health Soc Behav. 2012;53(4):482-97.

95. Nyundo A, Manu A, Regan M, Ismail A, Chukwu A, Dessie Y, Njau T, Kaaya SF, Smith Fawzi MC. Factors associated with depressive symptoms and suicidal ideation and behaviours amongst sub-Saharan African adolescents aged 10-19 years: cross-sectional study. Tropical Med Int Health. 2020;25(1): 54-69.

96. Atwine B, Cantor-Graae E, Bajunirwe F. Psychological distress among AIDS orphans in rural Uganda. Soc Sci Med. 2005;61(3):555-64.

97. Chi P, Li X. Impact of parental HIV/AIDS on children's psychological well-being: a systematic review of global literature. AIDS Behav. 2013;17(7):2554-74.

98. Cluver L, Boyes M, Orkin M, Sherr L. Poverty, AIDS and child health: identifying highest-risk children in South Africa. S Afr Med J. 2013;103(12): 910-5.

99. Cluver LD, Orkin M, Gardner F, Boyes ME. Persisting mental health problems among AIDS-orphaned children in South Africa. J Child Psychol Psychiatry. 2012;53(4):363-70 
100. Nabunya P, Padgett D, Ssewamala FM, Courtney ME, Neilands T. Examining the nonkin support networks of orphaned adolescents participating in a family-based economic-strengthening intervention in Uganda. J Commun Psychol. 2019:47(3):579-93.

101. Han CK, Ssewamala FM, Wang JS. Family economic empowerment and mental health among AIDS-affected children living in AIDS-impacted communities: evidence from a randomised evaluation in southwestern Uganda. J Epidemiol Community Health. 2013;67(3):225-30.

102. Karimli L, Ssewamala FM, Neilands TB, Wells CR, Bermudez LG. Poverty, economic strengthening, and mental health among AIDS orphaned children in Uganda: mediation model in a randomized clinical trial. Soc Sci Med. 2019;228:17-24.

103. Nyoni T, Nabunya P, Ssewamala FM. Perceived social support and psychological wellbeing of children orphaned by HIV/AIDS in southwestern Uganda. Vulnerable Children Youth Stud. 2019;14(4):351-63.

\section{Publisher's Note}

Springer Nature remains neutral with regard to jurisdictional claims in published maps and institutional affiliations.

Ready to submit your research? Choose BMC and benefit from:

- fast, convenient online submission

- thorough peer review by experienced researchers in your field

- rapid publication on acceptance

- support for research data, including large and complex data types

- gold Open Access which fosters wider collaboration and increased citations

- maximum visibility for your research: over $100 \mathrm{M}$ website views per year

At BMC, research is always in progress.

Learn more biomedcentral.com/submissions 